\title{
Balloon Retrograde Transvenous Obliteration for Treatment of Persistent Gastric Variceal Bleed in Patient With Hepatocellular Carcinoma
}

\author{
Jaimy Villavicencio Kim ${ }^{1}$, Ismail Elkhattib ${ }^{1}$, Daniela Guerrero Vinsard ${ }^{1}$ \\ 1. Internal Medicine, University of Connecticut Health Center, Farmington, USA
}

Corresponding author: Jaimy Villavicencio Kim, jaimyvk@gmail.com

\begin{abstract}
Gastric varices are often associated with formation of spontaneous portosystemic shunts that arise to relieve portal hypertension. Balloon retrograde transvenous obliteration (BRTO) is a procedure indicated to prevent recurrent gastric variceal bleeding. Its advantage is diverting blood flow towards the liver, but this can also worsen portal pressure and increase risk for ascites or esophageal variceal bleeding. Patients with gastric varices and concomitant hepatocellular carcinoma (HCC) usually have more advanced cirrhosis and lower possibility of treatment of HCC. BRTO is thought to preserve hepatic function from increased blood flow, possibly allowing better chances of treatment and survival in these patients.
\end{abstract}

Categories: Internal Medicine, Gastroenterology

Keywords: brto, gi bleed, gastric varices, hepatocellular carcinoma

\section{Introduction}

Gastric varices account for $20 \%$ of all variceal bleeding, and the one-year risk of bleeding is around $16 \%$ [1]. Classification is made according to their location into gastroesophageal varices (GOV1; extending to lesser curvature and GOV2; extending into fundus) and isolated gastric varices (IGV1; in fundus and IGV2; anywhere else in the stomach). They are often associated with formation of spontaneous left-sided portosystemic shunts, which arise to relieve portal hypertension or bypass portal venous obstruction. Gastrorenal shunts are the most common ( $80 \%-85 \%)$, but direct gastrocaval and gastrocaval via inferior phrenic vein are also commonly seen [2].

Evidence for primary prophylaxis for gastric variceal bleeding is scarce. Only medical management with non-selective beta-blockers is recommended [3]. However, balloon retrograde transvenous obliteration (BRTO) remains one of the first-line therapies to prevent re-bleeding from cardio-fundal varices. During this procedure, a balloon is inserted into the outflow vein of a shunt to allow injection of a sclerosing agent for occlusion. Therefore, careful evaluation of anatomy with CT scan or MRI is required prior to procedure to

Received 05/03/2020

Review began 05/29/2020 Review ended 06/19/2020 Published 06/24/2020

\section{() Copyright 2020}

Villavicencio Kim et al. This is an open access article distributed under the terms of the Creative Commons Attribution License CC-BY 4.0., which permits unrestricted use, distribution, and reproduction in any medium, provided the original author and source are credited. document presence of a portosystemic shunt. It has the advantage of not diverting blood to bypass the liver, but it can worsen portal pressure and increase risk for ascites or esophageal variceal bleeding [2]. This endovascular technique was perfected and is commonly used in Japan, yet it is not widely practiced in the United States. This is thought to be mainly due to lack of experience with use of sclerosant agents or due to the contradictory method of occluding a spontaneous shunt to relieve portal pressure (which is essentially why transjugular intrahepatic portosystemic shunt [TIPS] is done) [4].

\section{Case Presentation}

A 67-year-old male with a past medical history of untreated hepatitis $\mathrm{C}$ and hypertension was admitted after experiencing nausea, lightheadedness and a syncopal episode resulting in trauma to his head. En route to the hospital, the patient had one episode of hematemesis, followed by two additional episodes in the emergency department. Vital signs were as follows: heart rate 100 beats per minute, respiratory rate 16 breaths per minute, blood pressure $131 / 71 \mathrm{mmHg}$ and temperature $94.3^{\circ} \mathrm{F}$. The patient was oriented to person, place and time. His abdomen was soft, non-distended and non-tender to palpation. Pertinent laboratory tests included hemoglobin $9.5 \mathrm{~g} / \mathrm{dl}$, hematocrit $29.5 \%$, platelets $197 \mathrm{~K} / \mathrm{\mu L}$, blood urea nitrogen (BUN) $22 \mathrm{mg} / \mathrm{dl}$, creatinine $0.8 \mathrm{U} / \mathrm{L}$, aspartate aminotransferase (AST) $112 \mathrm{U} / \mathrm{L}$, alanine aminotransferase (ALT) $76 \mathrm{U} / \mathrm{L}$, total bilirubin $0.5 \mathrm{mg} / \mathrm{dl}$, alkaline phosphatase $18 \mathrm{U} / \mathrm{L}$, albumin $3.2 \mathrm{~g} / \mathrm{dl}$, lactic acid $3.1 \mathrm{mmol} / \mathrm{L}$, prothrombin time 11.8 seconds and international normalized ratio (INR) 1.0. Octreotide infusion, ceftriaxone and a proton-pump inhibitor were promptly started, along with transfusion of three units of blood due to persistent bleeding.

Urgent endoscopy was performed, where a significant amount of red blood was seen in the gastric fundus with an area of active bleeding near the gastroesophageal junction. No esophageal varices were seen. Attempts to control the hemorrhage endoscopically were unsuccessful due to large amount of active bleeding obscuring visibility. CT scan of the abdomen showed a 6-cm mass in the right lobe of a cirrhotic liver (suspected to be hepatocellular carcinoma [HCC]) and one large gastric varix with a gastrorenal shunt 


\section{Cureus}

(Figure 1). Importantly, there was no evidence of portal vein or splenic vein thrombosis.

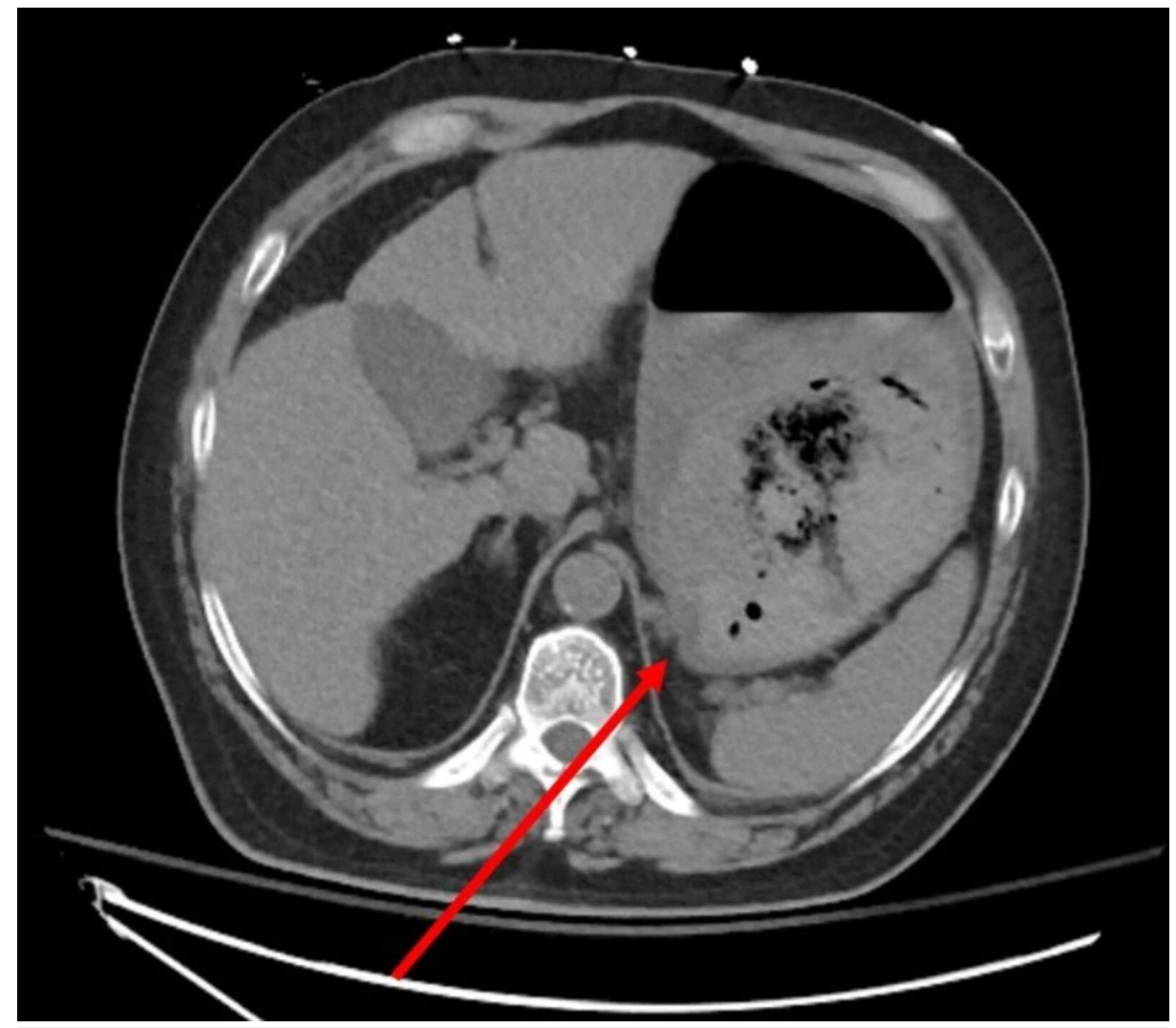

FIGURE 1: CT scan of the abdomen

The red arrow shows gastric varices.

Initially, left-sided TIPS was attempted, but multiple attempts to pass from left portal vein to left hepatic vein were unsuccessful due to challenging anatomy. The patient required multiple blood products.

Eventually, the patient underwent BRTO. His left renal vein was accessed via the right internal jugular vein, the balloon was inflated and a sclerosing agent was injected into the bleeding varix. This was followed by coiling of the same varix, resulting in occlusion of the portosystemic shunt (Figure 2). The patient had no further episodes of bleeding and was discharged a few days later. He was ultimately diagnosed with HCC (Figure 3). 


\section{Cureus}

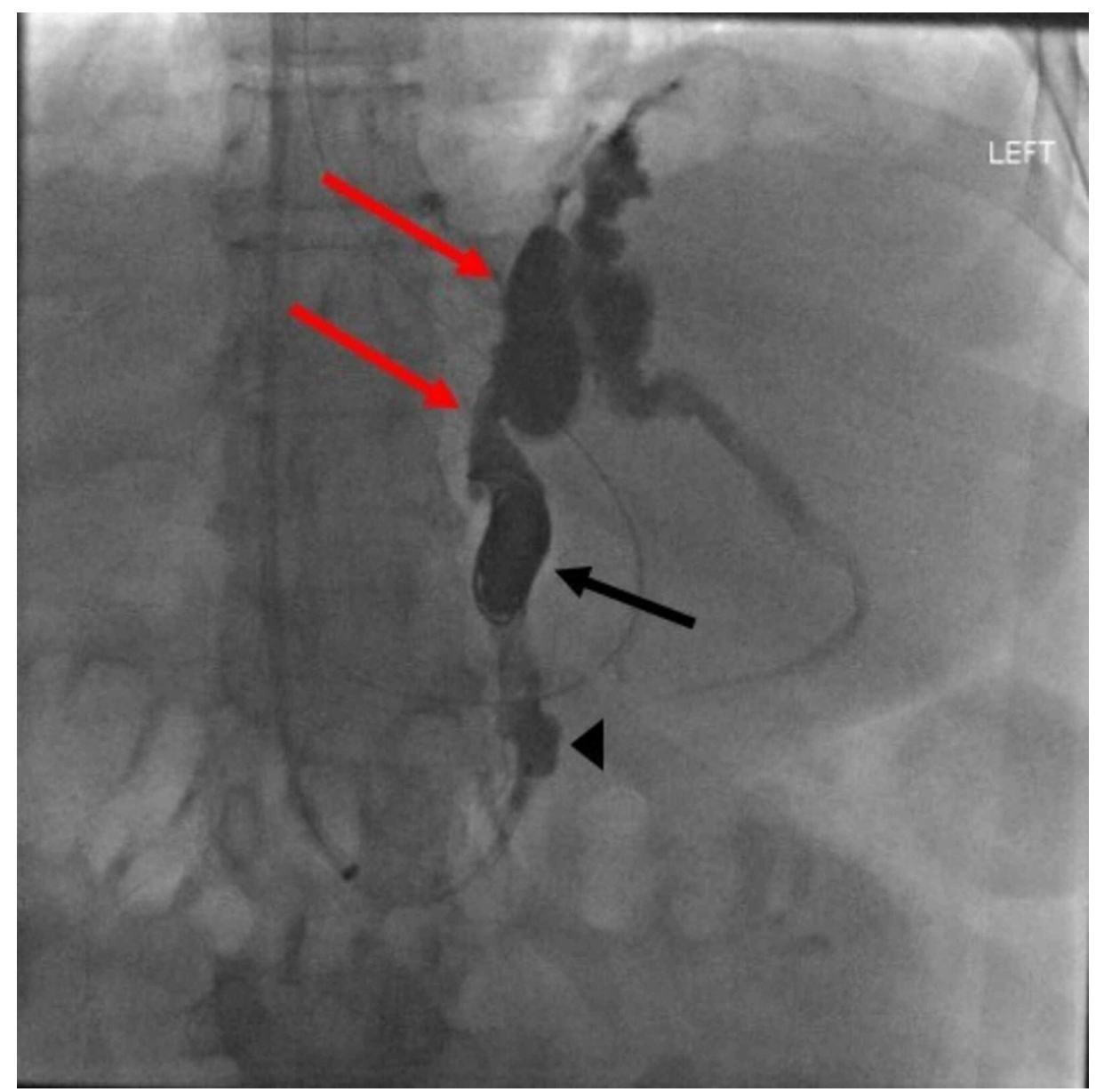

\section{FIGURE 2: Fluoroscopy image of the BRTO procedure}

The arrow head points at inflated balloon. The black arrow shows coiling. The red arrow shows gastrorenal shunt.

BRTO, balloon retrograde transvenous obliteration. 


\section{Cureus}

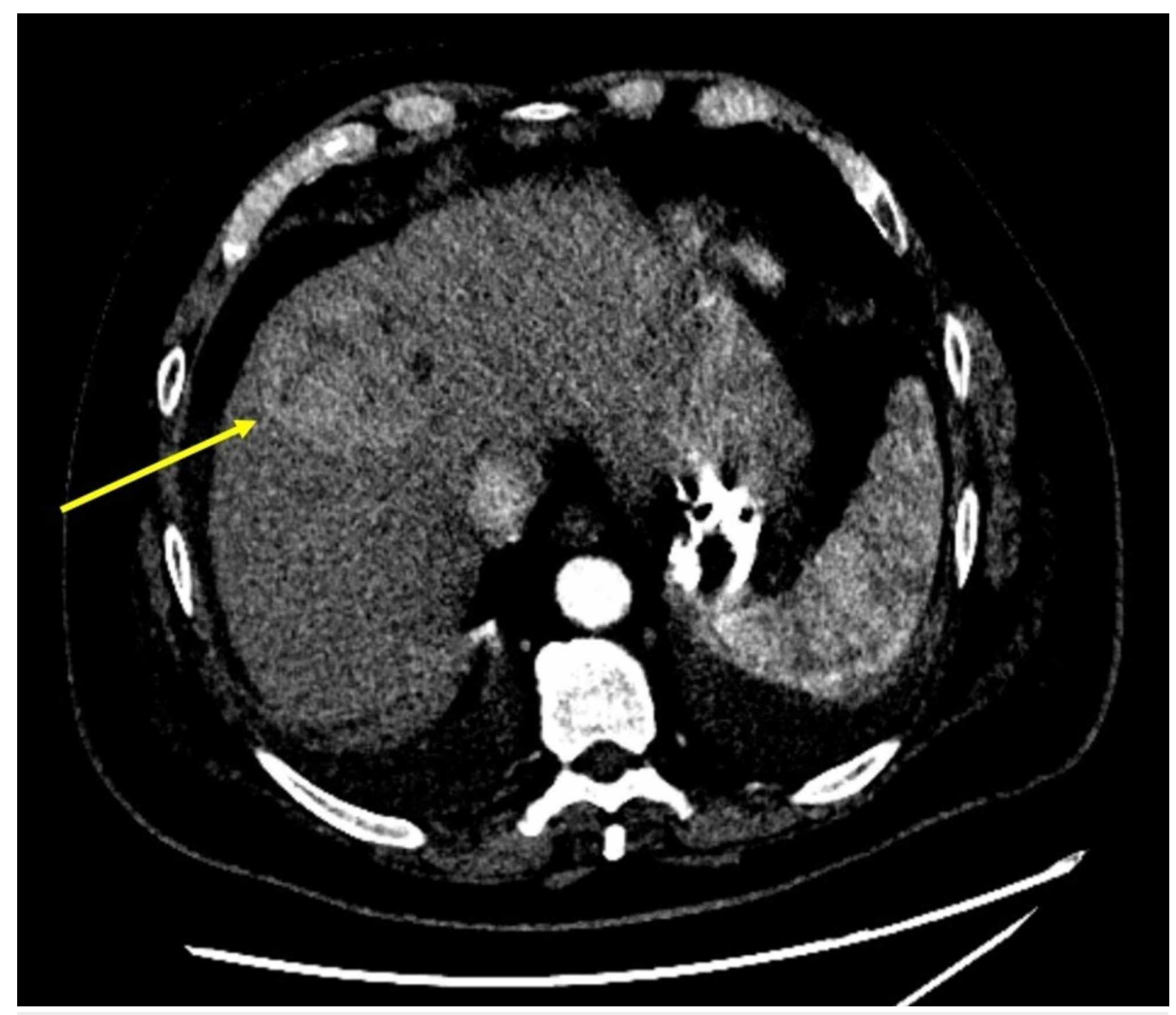

FIGURE 3: Arterial phase of triple phase CT abdomen

The yellow arrow points at hepatocellular carcinoma.

\section{Discussion}

In the American Associated for the Study of Liver Diseases (AASLD) guidelines, BRTO is indicated primarily for prevention of recurrent gastric variceal bleeding [3]. It can be used in patients who are at high risk for TIPS including elevated Model for End-Stage Liver Disease (MELD) score, right-sided heart failure or hepatic encephalopathy. Disadvantages are mainly esophageal variceal bleeding or worsening ascites, as essentially portal pressure worsens with the occlusion of the spontaneous hepatofugal shunt [4]. Contraindications include portal or splenic vein thrombosis without other portosystemic collaterals to provide adequate mesenteric or splenic venous outflow following BRTO [5].

A prospective study showed that patients with gastric variceal bleeding and concomitant HCC usually have more advanced cirrhosis and lower possibility of HCC treatment, due to bleeding-related hepatic decompensation. Another study showed that patients with HCC and esophagogastric varices have overall poorer liver functional reserve [6]. Although BRTO has its disadvantages, its ability to divert blood flow towards the liver is thought to possibly preserve hepatic function. This might make patients with HCC and gastric varices good candidates for BRTO, allowing better possibility for treatment. Further long-term studies are needed to evaluate prognosis and complications of BRTO in these patients.

Patients with variceal bleeding and HCC have worse outcomes compared to those without HCC, and death is most commonly related to hemorrhage. Variceal bleeding is known to be an independent risk factor for overall survival in newly diagnosed HCC and an important component in prognosis [7].

\section{Conclusions}

The role of BRTO for primary prevention for gastric variceal bleeding in HCC patients is still obscure. Investigating the benefit of BRTO could be important if there is a possibility of improving survival in these patients. Lack of experience with this procedure could be a limiting factor, but we expect BRTO to be increasingly used in the United States.

\section{Additional Information}

\section{Disclosures}

Human subjects: Consent was obtained by all participants in this study. Conflicts of interest: In 
compliance with the ICMJE uniform disclosure form, all authors declare the following: Payment/services info: All authors have declared that no financial support was received from any organization for the submitted work. Financial relationships: All authors have declared that they have no financial relationships at present or within the previous three years with any organizations that might have an interest in the submitted work. Other relationships: All authors have declared that there are no other relationships or activities that could appear to have influenced the submitted work.

\section{References}

1. Boregowda U, Umapathy C, Halim N: Update on the management of gastrointestinal varices. World J Gastrointest Pharmacol Ther. 2019, 10:1-21. 10.4292/wigpt.v10.i1.1

2. Basseri S, Lightfoot CB: Balloon-occluded retrograde transvenous obliteration for treatment of bleeding gastric varices: case report and review of literature. Radiol Case Rep. 2016, 11:365-369.

10.1016/j.radcr.2016.09.009

3. Garcia-Tsao G, Abraldes JG, Berzigotti A, Bosch J: Portal hypertensive bleeding in cirrhosis: rsk stratification, diagnosis, and management: 2016 practice guidance by the American Association for the study of liver diseases. Hepatology. 2017, 65:310-335. 10.1002/hep.28906

4. Saad WEA: The history and evolution of balloon-occluded retrograde transvenous obliteration (BRTO): from the United States to Japan and back. Semin Intervent Radiol. 2012, 28:283-287. 10.1055/s-0031-1284454

5. Saad WEA, Darcy MD: Transjugular intrahepatic portosystemic shunt (TIPS) versus balloon-occluded retrograde transvenous obliteration (BRTO) for the management of gastric varices. Semin Intervent Radiol. 2011, 28:339-349. 10.1055/s-0031-1284461

6. Hsieh WY, Chen PH, Lin IY: The impact of esophagogastric varices on the prognosis of patients with hepatocellular carcinoma. Sci Rep. 2017, 7:42577. 10.1038/srep42577

7. Kim JH, Sinn DH, Kim K: Primary prophylaxis for variceal bleeding and the improved survival of patients with newly diagnosed hepatocellular carcinoma. Dig Dis Sci. 2016, 61:3354-3362. 10.1007/s10620-016 4255-6 